\section{Original Research}

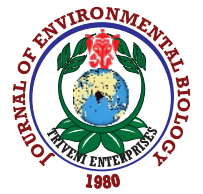

DOI : http://doi.org/10.22438/jeb/415(SI)/MS_33
Journal Home page : www.jeb.co.in $\star$ E-mail : editor@jeb.co.in Journal of Environmental Biology CODEN: JEBIDP
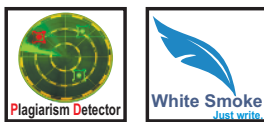

\title{
Environmental and socio-economic benefits of integrated fisheries management in Korea
}

\author{
Sang-Go Lee ${ }^{1}$, Md. Hashmi Sakib ${ }^{1,2 *}$ and M. Aminur Rahman ${ }^{1,3}$ \\ ${ }^{1}$ World Fisheries University Pilot Programme, Pukyong National University, 365 Sinseon-ro, Nam-gu, Busan 48547, Republic of Korea \\ ${ }^{2}$ Department of Agricultural Extension and Rural Development, EXIM Bank Agricultural University Bangladesh, Chapainawabganj 6300, Bangladesh \\ ${ }^{3}$ Department of Fisheries and Marine Bioscience, Faculty of Biological Science and Technology, Jashore University of Science and Technology, \\ Jashore 7408, Bangladesh
}

*Corresponding Author Email : sakib20067@gmail.com

\begin{abstract}
Aim: Seasonal closure was integrated with fisheries stock rebuilding plans (FSRP) to observe the changes in productivity and socio-economic status of fishery sector.

Methodology: Ten commercial species namely sandfish, blue crab, octopus, tokobushi abalone, skate ray, cod, yellow croaker, filefish, Korean flounder and purplish Washington clam were considered from FSRP to conduct this study. Closed season was incorporated with FSRP in terms of sandfish, blue crab, octopus, skate ray and yellow croaker fishery. Year-round open fishery was applied for other five species (viz., tokobushi abalone, cod, filefish, Korean flounder and purplish Washington clam) in FSRP. Annual fish landing data were collected from 1991 to 2016. Changing patterns in catch history, revenue and social status were evaluated.

Results: Due to achieve enough time to breed and feed during seasonal closure, the production was increased dramatically in five marine species, sandfish, blue crab, octopus, skate ray, and yellow croaker. Besides, $86 \%$ increased revenue was earned from the integrated policy. Livelihood improved during the last 10 years of FSRP.

Interpretation: Mixed catch, economic loss of fishermen and biology of species are the key factors for continuing integrated fisheries management policy successfully.
\end{abstract}

Key words: FSRP, Integrated management, Marine species, Seasonal closure, Socio-economic

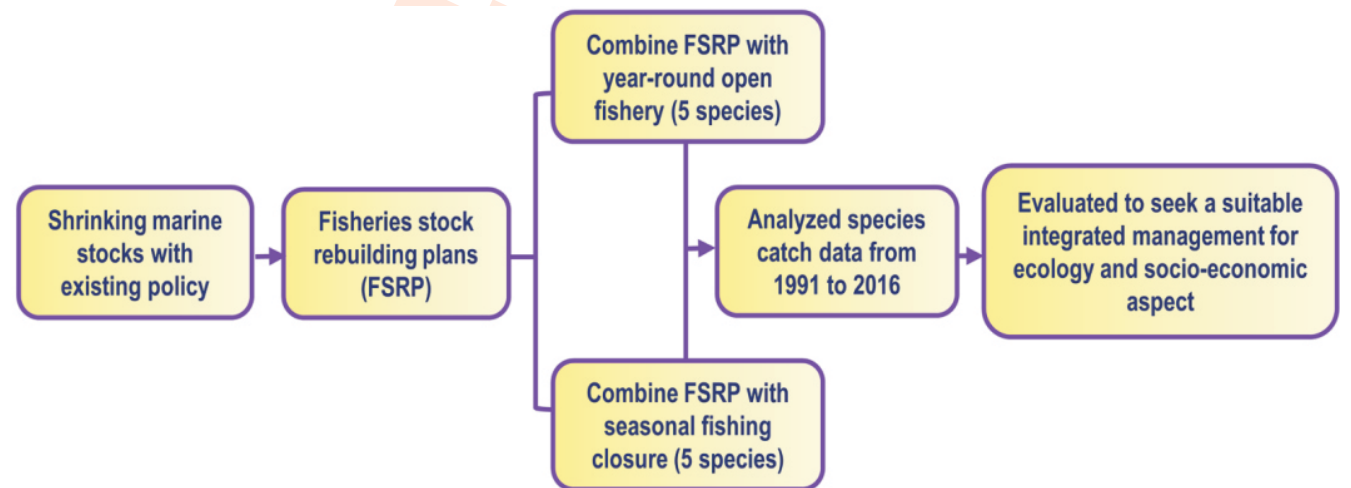

How to cite : Lee, Sang-Go, Md. Hashmi Sakib and M. Aminur Rahman: Environmental and socio-economic benefits of integrated fisheries management in Korea. J. Environ. Biol., 41, 1390-1398 (2020). 


\section{Introduction}

World's fishing has contributed to human welfare, income generation, augmenting employment and meeting increased food demand. On the other hand, it has also imposed a firm threat on fishery resources and marine ecosystems by diminishing stock abundance and biodiversity, and compromising the economic viability of fishing industry (Ye et al., 2013; Rice and Garcia, 2011). The present situation compels United Nations to draw attention towards sustainable resource management in the oceans (UN, 2017). In this regard, a reduction in only fishing effort should counteract the increase in global per capita fish intake registered over the last five decades (Merino et al., 2014; FAO, 2014). South Korea has increased the fishing pressure on many marine resources in a very short period of time (Lee and Midani, 2014; Zhang et al., 2007). This situation has compelled the entire nation and experts to think about exploited stock rebuilding to make sound marine ecosystem. Though the conditions vary from species to species, stock assessment carried out in coastal and offshore areas in Korea have revealed that total fish harvest dropped consistently from 1.7 million tons in1986 to 1.0 million tons in 2004 (Lee, 2010). Remained fishing pressure can be one of the potential causes to deplete fish stocks by 3.5 million tons in a decade (Lee and Midani, 2014). Additionally, in 2000s, the proportion of adult fish in the catches was lower than $20 \%$ (Lee, 2010). This highlights that the reproductive capacity of fish stocks has sharply decreased, which has not only resulted in the decline of fishery resources but also increased the percentage of immature fish.

Besides fishing pressure, climatic variations, unbalanced catch composition, environmental contamination and habitat destruction are other factors contributing to the decline in biomass of marine resources (Zhang et al., 2007). Moreover, comanagement of fishing grounds with neighboring countries has not been effectively carried out due to territorial conflicts. Some of the fishing management strategies conventionally adopted by the Korean Government includes closure at fishing time, closure in areas, mesh size and fishing gear regulations as well as input control. Conventional fisheries management strategies has solely focused on harvesting within fisheries and maintaining fishing industry rather than on rebuilding stocks. Besides, management policies has been also implemented ineffectively in accordance with stock data. In particular, the characteristics of coastal and offshore multi-species fisheries put the ultimate challenges in implementing management policies for each fish species. Likewise, another potential reason of depletion in fisheries resources is the failure of effectively refrain fishers from overfishing of juvenile fishes due to mix-fishing (Lee and Midani, 2014). As a result, the Korean government has taken step to rebuild fish stocks as the core objective of fisheries policy.

Seasonal closure improves the fish stock health by giving provision to spawn and grow for longer period. Therefore, the production of fish has significantly increased in the following years. On the other hand, the government of Korea has launched the Fish Stock Rebuilding Plan (FSRP), including fishing closure in 2006 to rebuild fishery more sustainably. Hence, there is a huge possibility to get remarkable landing of fishes from this policy integration. As a result, main stake holders, fishermen will get more revenue from extra production to improve their socioeconomic status. Thus, FSRP and seasonal closure evaluation of integrated FSRP will help to take suitable decision for making the present Korean fisheries policy more robust. By considering backdrops, this study aims to combine policies between FSRP and seasonal closure towards observing the effect in fish landing and increased economic return for seeking a stable and productive fishery in Korea.

\section{Materials and Methods}

Fish stock enhancement program (FSEP) is one of the major tools of rebuilding fishery stocks. Fisheries Resources Agency (FIRA) involved in fish stock enhancement programs including the construction and installation of artificial reefs, production and release of fish seeds, building and managing marine ranches, and marine forest (marine reforestation) to restore and recover fish stocks. The main target of fish stock enhancement program is to increase fish stocks and fisher's income by improving the marine environment and restoring productivity for natural population of fish (FIRA, 2017). The artificial reef program was implemented in 1971 to increase fisheries resources by creating habitats and spawning grounds. The fry stocking program has been operating since 1976 in order to complement and enhance the recruitment of fishery resources by directional fry release of jumbo shrimp, blue crab, flat fish, kuruma prawns, jacopevers and abalone. The marine ranching program is living conducted in coastal areas since 1998 (Fig. 1). Since 2009, the marine seaweeds forest program has been playing an important role in making a suitable habitat for different type of marine organisms, including fishes (FIRA, 2017). The program focus on the reestablishment of marine seaweed forests destroyed by some factors such as rise in sea temperature, marine pollution and algae eating animals.

In Korea, fisheries management noticeably depends on input control measures such as vessel licensing, gear restriction, mesh size limitation, vessel buyback, and also seasonal closure as the potential technical measures to reduce overexploitation (Lee and Midani, 2015). Profitable fishery always lures fishermen to increase fishing operation for harvesting more to maximize their income (Gordon, 1954). Stop fishing for some days is being widely practiced by the fisheries governance authority to keep optimum harvesting to conserve fish for reducing adverse effect on stock biomass (Ichinokawa et al., 2015). The fishing day limitation is a useful strategy for allowing brood stocks to spawn and juveniles to grow (Simões et al., 2017). Although Korean fishery is managed by regulating fishing gears, efforts, and 


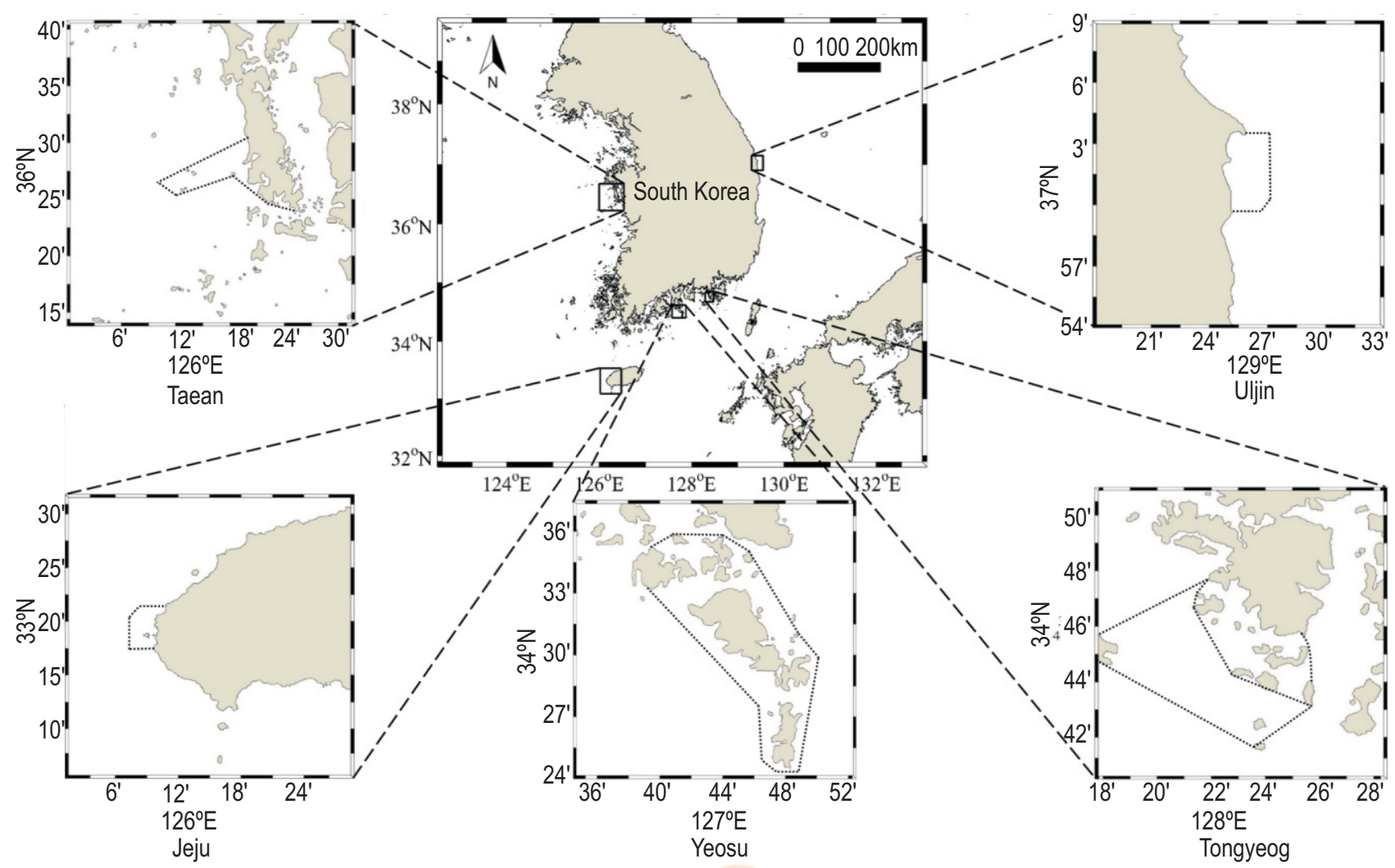

Fig. 1: Map of coastal marine ranches installation areas in 2014

seasonal closure to improve the health of resources in the sea, however, the catch level still remains to decline (Lee and Midani, 2015). Hence, the stock rebuilding plans were started in 2006 for making a sound ecosystem in the sea by implementing some stock enhancement programs (Lee and Midani, 2014). These policies aim to enhance fish biomass by combining some technical measures, for instance, sea grass plantation, juvenile fish release, artificial coral installation to make a suitable sea bed for living and breeding marine fishes. Species, those are considered to rebuild within certain period of time, are very important to know about their biological status for further making a management decision to ensure sustainability of resources.

Ten commercially important species in FSRP, such as sandfish (Arctoscopus japonicus), blue crab (Portunus pelagicus), octopus (Octopus minor), tokobushi abalone (Haliotis discus), skate ray (Hongeo koreana), cod (Gadus microcephalus), yellow croaker (Larimichthys polyactis), filefish (Stephanolepis cirrhifer), Korean flounder (Paralichthys olivaceus) and purplish Washington clam (Saxidomus purpuratus) are considered to evaluate management policies to get a fruitful way to implement target-oriented measures. Among these species, tokobushi abalone, cod, filefish, Korean flounder and purplish Washington clam have been caught all year long without fishing closure until now. However, the rest five marine species, sandfish, blue crab, octopus, skate ray and yellow croaker landings were considered to observe the effect of integration between FSRP and seasonal fishing closure management practices. To understand the variations in biomass during management term, total production in metric tons (MT) of five species, which are included in seasonal closure policy was calculated by the formula:

$$
T P C=\sum_{i=1}^{n} P_{t}
$$

where, TPC is the total annual production (MT) of all species regarding closed season policy; $n$ represents the total number of species and $P_{t}$ indicates catch (MT) of species at time t. Similarly, total annual production of year-round open fishing species was calculated by the formula :

$$
\text { TPOF }=\sum_{i=1}^{n} P_{t}
$$

where, TPOF denotes the total amount of annual production (MT) of all species concerning year-round open fishing policy; $n$ represents the total number of species and $P_{t}$ corresponds catch (MT) at time t.

According to Lee and Rahman (2018), the amount of gained landings were computed on yearly basis. 2006 was considered as base year. The landing value in 2006 was subtracted from the landing value in 2007 to get the increased amount of landing for a specie. Likewise, the landing value of 
2006 was subtracted from each year between 2007 and 2016. Thereafter, 10 positive or negative increased landing (MT) values were obtained. Then, only positive landing values were summed up to get total increased catch amount of that stock was expressed as:

$$
\mathrm{TIC}=\sum_{i=1}^{n} P_{i}\left[\text { where }, P_{i}>0\right]
$$

where, TIC is the total increased catch in ten years from 2007 to 2016. $P_{i}$ indicates the increased catch (MT) value each year than catch value in base year 2006 during the period of FSRP.

Data were procured from an official data bank of Korean Fisheries Association (KFA, 2017). Catch data were obtained between 1991 and 2016. However, the starting year of FSRP was 2006. Therefore, Landing data were opted from 2006 to 2016 for each specie to ascertain the effect of FSRP. The collected data were combined, coded, tabulated and analyzed as per aim of the study.

\section{Results and Discussion}

Production in seasonally closed fishery: To begin with, sand fish landing was more than 4,500 metric tons in 1991 and it sharply declined to 1,500 metric tons in 1993. Again, it showed the catch fluctuating between 1994 and 2006. Apparently, harvesting began to increase just after 2006 and continued till 2016. Besides, landing of blue crab also changed negatively before 2006. In 1991 , the catch was more than 18,000 metric tons. However, that dropped in 2004. Just after 2006, again catch of blue crab had begun to rise and rose until 2010. Blue crab harvesting continued to reduce between 2011 and 2016. Historical catches of octopus were not similar with other species. Although octopus was fluctuated between 1991 and 2000, but certainly improved its landings from 2006 to 2016 (Fig. 2). Yellow croaker showed a considerable reduction in catches between 1991 and 2003. Again production started to get back at an optimistic level since 2007. From 2007 to 2016, the production continued with a higher rate as compared to the production of previous years of FSRP. Before FSRP, skate ray fishery was leading about to collapse. In contrast, a sharp rise happened for skate ray fishery in FSRP period and abled to keep producing above average production level. In addition, TCP also showed higher amount in landing with 10 years of FSRP (Fig. 2). FSRP with seasonally fisheries closure augmented fish catches successfully than previous years. Seasonal closure might have played a role with FSRP influence FSRP to make a healthy fishery for the coastal community in South Korea.

Production in year-round open fishery: In year-round open fishery, production scenarios of five fisheries are displayed in Fig. 3. However, almost all species declined in catches since 1991. Surprisingly, the production of cod improved noticeably during the period 1991-2016, whereas Korean flounder began to improve in landings after six years of beginning of FSRP. Between 1997 and 2004, tokobushi abalone declined consistently. Again production was hiked suddenly from 2004 and continued upto 2007 because of potential stimulation of FSRP. However, during the last couple of years, landings of tokobushi abalone had fell down critically towards disappearance. Similarly, filefish was produced lower than the average line during FSRP tenure. In contrast, purplish Washington clam gave a good amount of landings until 2005 but suddenly dropped in catches from 2005 to 2016 (Fig. 3). Total amount of production (TPOF) in year-round open fishery was considerably lower during FSRP.

Production increment in FSRP: Sandfish, blue crab/swimming crab, octopus, skate ray, yellow croaker and cod stocks successfully improved in production, whereas rest four species such as filefish, Korean flounder and purplish Washington clam failed to establish their population effectively. The increased percentages in production of sandfish, blue crab/swimming crab, octopus, skate ray, yellow croaker and cod were 120, 107, 29, 116, 127 and 362, respectively (Table 1, 2).

In contrast, tokobushi abalone, file fish, Korean flounder and purplish Washington clam dropped by $63 \%, 29 \%, 25 \%$, and $44 \%$, respectively (Table 1, 2). Although decline in production of some species happened during FSRP, however six species gained through this program. Nevertheless, all the species gained abundance during FSRP with seasonal closure. Therefore, along with FSRP, seasonal closure could have made fishery more viable.

Environmental benefits: Although it is difficult to evaluate a comprehensive fisheries management policy based on fisheries stock enhancement programs (FSEP) within only 10 years, some vivid emerging improvements were depicted at the level of species abundance. Vital FSEP tools not only enhanced biological components in the marine ecosystem but also encouraged physical and biological progress to make a sound habitat for lifting up the stock level. In addition, integration of closed fishing season with FSRP helps to increase the fish stock productivity as expected (Table 1).

Until now, a total of 16 FSRPs have been established (Lee and Rahman, 2018), including the special programs on sandfish, blue crab, octopus (East Sea), skate ray (Yellow Sea), cod, yellow croaker, filefish, Korean flounder (East Sea), however, rest FSRPs were considered for nationwide. In 2008, ten species were considered to reach target level of recovery based on their stock biomass from catch data. Seasonally closed fishery acted as support with stock rebuilding plans to progress fish stock level. As a result, the estimated 10 targeted fish stocks recovered amount accounted for 455, 409 MT (Table 3, Table 4).

Economic profits: FSRP has contributed to rebuild fishery stocks in a relatively short period. Observations indicate a 

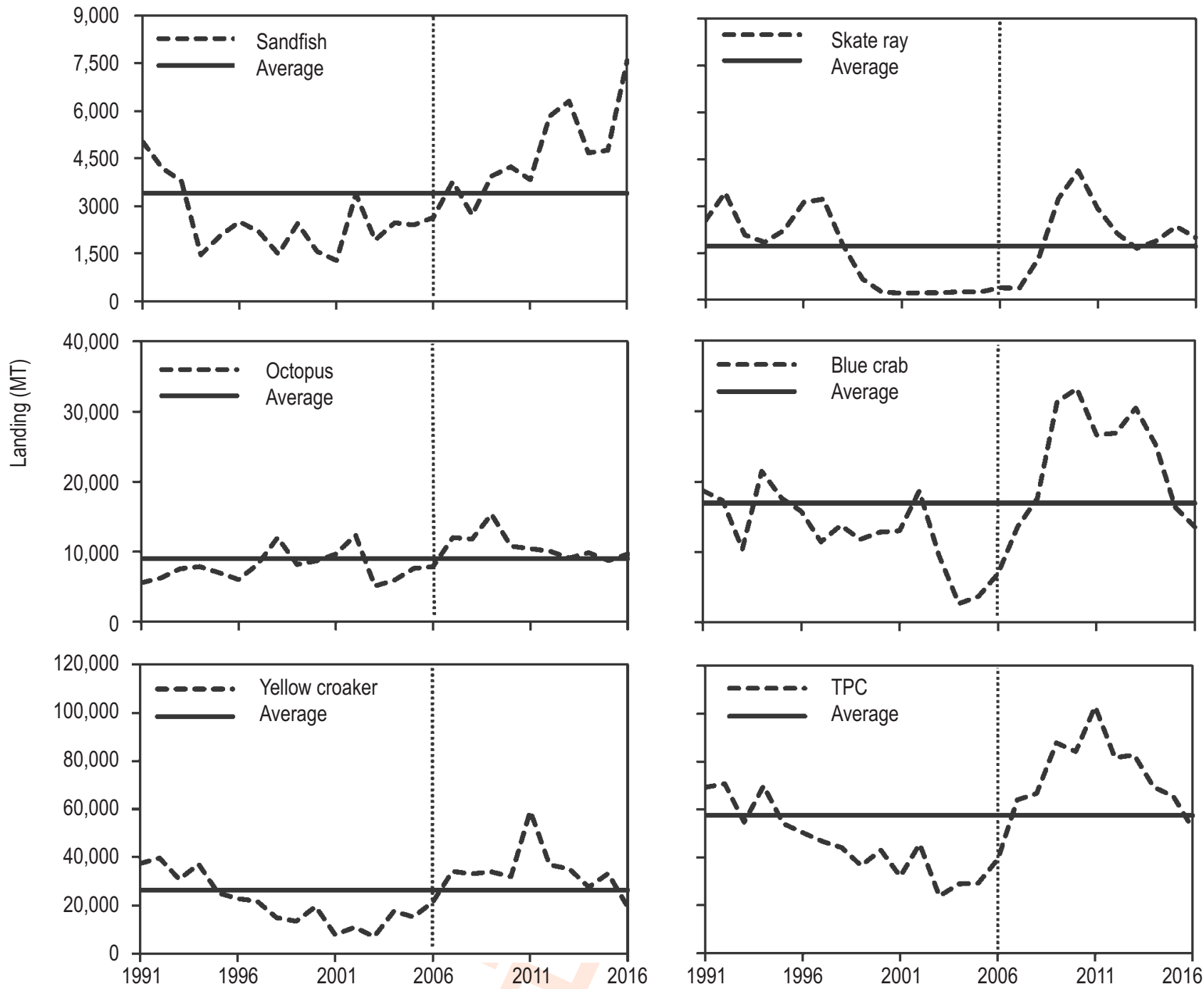

Fig. 2 : Annual production (1991-2016) of seasonally closed fishery.

positive change in fish stock biomass during FSRP project operation. Likewise, an increment of catches triggered more revenues from targeted individual fisheries. Total revenue was computed by multiplying market price with total recovery amount of fish over the period of 10 years to evaluate economic contribution of FSRP. Here, revenue in FSRP with seasonally closed fishery was around six-folds higher than FSRP with yearround fishery. Moreover, from 2007 to 2016, total revenue of FSRP increased by 4184.77 million USD in seafood sector (Table $3,4)$. The revenue increased to $86 \%$ in terms of FSRP with seasonal closure. In contrast, only $14 \%$ increased revenue counted from year-round open fishery. Among all, yellow croaker, blue crab and Korean flounder were the leading contributors in economy (Table 5).

In the past, on average, yearly basis increment in fishing income was USD 206.3 million amid of FSRP operation (Lee,
2007). In 10 years, total increase of 0.45 million MT fish contributed to the domestic fish market (Table 3, 4). In Korean market, this is an important fact taking into consideration that $70 \%$ of the food supply is imported from overseas; with the value of imported fish and seafood estimated to be 3.8 billion USD (Agriculture and Agri-Food Canada, 2015). It indicates that integrated policy works to make more stable seafood business for domestic people. So, the employed people in seafood industry are being benefitted from fish stock rebuilding plan by generating higher revenue than before.

Social welfare: Effective and voluntary participation of fishermen community in promoting self-regulatory fishery is one of the main objectives of FSRP. As a novel concept in Korean fisheries management, community-based fishery allows fishermen to deliver unique ideas to manage resources as effectively as 
Table 1 : Landing nature before and after FSRP with seasonal fishing closure

\begin{tabular}{llllll}
\hline Landings & $\begin{array}{l}\text { Sandfish } \\
\text { (MT) }\end{array}$ & $\begin{array}{l}\text { Blue crab } \\
\text { (MT) }\end{array}$ & $\begin{array}{l}\text { Octopus } \\
\text { (MT) }\end{array}$ & $\begin{array}{l}\text { Skate ray } \\
\text { (MT) }\end{array}$ & $\begin{array}{l}\text { Yellow croaker } \\
\text { (MT) }\end{array}$ \\
\hline Average landing from 1996 to 2005(Before FSRP) & 2167 & 11323 & 8402 & 1021 & 15161 \\
Average landing from 2007 to 2016 (After FSRP) & 4767 & 23486 & 10800 & 2204 & 34489 \\
Change(\%) & 120 & 107 & 29 & 116 & 127 \\
\hline
\end{tabular}

Table 2 : Landing nature before and after FSRP with year-round open fishery

\begin{tabular}{|c|c|c|c|c|c|}
\hline Landings & $\begin{array}{l}\text { Tokobushi } \\
\text { abalone } \\
\text { (MT) }\end{array}$ & $\begin{array}{l}\text { Cod } \\
\text { (MT) }\end{array}$ & $\begin{array}{l}\text { Filefish } \\
\text { (MT) }\end{array}$ & $\begin{array}{l}\text { Korean } \\
\text { flounder } \\
(\mathrm{MT})\end{array}$ & $\begin{array}{l}\text { Purplish Washington } \\
\text { clam } \\
\text { (MT) }\end{array}$ \\
\hline Average landing from 1996 to 2005 (Before FSRP) & 70 & 1725 & 3961 & 14352 & 4036 \\
\hline Average landing from 2007 to 2016 (After FSRP) & 26 & 7970 & 2797 & 10818 & 2242 \\
\hline Change (\%) & -63 & 362 & -29 & -25 & -44 \\
\hline
\end{tabular}

Table 3 : Economic gain of FSRP with seasonally closed fishery

\begin{tabular}{llllll}
\hline Year & Sandfish & Blue crab & Octopus & Skate ray & Yellow croaker \\
\hline 2006 & 2,647 & 6,894 & 7,894 & 392 & 21,428 \\
2007 & 3,769 & 13,606 & 12,033 & 375 & 34,221 \\
2008 & 2,720 & 17,596 & 11,838 & 1,343 & 33,200 \\
2009 & 3,939 & 31,302 & 15,386 & 3,254 & 34,033 \\
2010 & 4,236 & 33,193 & 10,813 & 4,131 & 31,931 \\
2011 & 3,834 & 26,608 & 10,421 & 59,226 \\
2012 & 5,836 & 26,861 & 10,080 & 2,925 & 36,840 \\
2013 & 6,306 & 30,448 & 9,109 & 1,123 & 35,280 \\
2014 & 4,678 & 25,310 & 9,881 & 1,889 & 27,638 \\
2015 & 4,762 & 16,374 & 8,753 & 2,349 & 33,254 \\
2016 & 7,593 & 13,558 & 9,683 & 2,000 & 19,271 \\
TIC (MT) & 21,203 & 165,916 & 29,057 & 18,137 & 132,771 \\
Price(2016)(\$MT) & 1,241 & 11,954 & 14,113 & 5,350 & 8,022 \\
Increased revenue & 26.31 & 1983.36 & 410.08 & 97.03 & 1065.09 \\
(Million US\$) & & & & & \\
\hline
\end{tabular}

possible through improving awareness and understanding on current situation to implement FSRP. Effectiveness of community-based FSRP can be maximized by ensuring active participation of fishermen.

Before selecting the stock of a target species for enhancing, an agreement was made between the fishery resource management committee and fishermen's organizations. The purpose of this agreement was to stimulate voluntary and active participation of fishermen to maximize the effectiveness of FSRP in connection to community-based management associations. Tasks were made voluntarily by fishermen to refrain themselves from roaming for fishing beyond limits, using excess gears by vessels and disturbing in spawning grounds. The Science Committee arranged conferences to make a fruitful avenue to ensure active participation of fishermen. Eventually, many fisheries restrictions were watched and found limited unlawful fishing.
Korean fisheries rebuilding relies on voluntary participation of fishermen community for effective stock enhancement through some effective stock enhancement programs. Besides many strategies were taken to ensure better participation by providing opinion, managing resources and stopping illegal fishing. Accordingly, strengthen communitybased fisheries management imposes losses upon fishermen during rebuilding stock for accepting to reduce the amount of catch from fishermen organizations (Lee and Rahman, 2018).

During the entire FSRP period, the government supported fishermen by taking some fruitful steps to stabilize the market for ensuring active participation. For example, some specific support was made to fix losses such as support on reducing fishing days, improvement of habitat for small fish and also avoidance by-catches. Expenditure to displace fishing gear and training of fishermen was aided for minimizing losses (Kim, 2004). 
Table 4 : Economic gain of FSRP with year-round open fishery

\begin{tabular}{llllll}
\hline Year & TA & C & FF & KF & PWC \\
\hline 2006 & 54 & 6,810 & 1,071 & 5,218 & 3,399 \\
2007 & 62 & 7,533 & 2,998 & 7,326 & 3,422 \\
2008 & 102 & 5,395 & 2,631 & 5,175 & 2,672 \\
2009 & 34 & 6,870 & 8,280 & 5,107 & 1,918 \\
2010 & 27 & 7,289 & 3,475 & 6,671 & 1,950 \\
2011 & 3 & 8,585 & 1,606 & 6,709 & 2,314 \\
2012 & 5 & 8,682 & 1,419 & 6,488 & 2,037 \\
2013 & 5 & 9,133 & 1,295 & 18,171 & 2,199 \\
2014 & 10 & 13,402 & 2,418 & 18,804 & 2,335 \\
2015 & 4 & 7,820 & 2,040 & 17,753 & 1,828 \\
2016 & 5 & 4,994 & 1,805 & 15,977 & 1,741 \\
TIC (MT) & 56 & 14,834 & 17,257 & 56,155 & 23 \\
Price(2016)(\$MT) & 55,706 & 5,015 & 6,163 & 7,460 & 4,956 \\
Increased revenue(Million US\$) & 3.12 & 74.4 & 106.35 & 418.92 & 0.11 \\
\hline
\end{tabular}

$\mathrm{TA}=$ Tokobushi abalone $\mathrm{C}=\mathrm{Cod} ; \mathrm{FF}=$ Filefish $; \mathrm{KF}=$ Korean flounder; $\mathrm{PWC}=$ Purplish Washington clam

Table 5 : Economic contribution of management policies.

\begin{tabular}{llll}
\hline Policy & Species & \multicolumn{2}{c}{ Increased revenue } \\
\cline { 3 - 3 } & & Million US\$ & Percent (\%) \\
\hline FSRP with seasonally closed fishery & Sandfish & 26.31 & 0.628 \\
& Blue crab & 1983.36 & 47.394 \\
& Octopus & 410.08 & 9.799 \\
& Skate ray & 97.03 & 2.318 \\
& Yellow croaker & 1065.09 & 25.451 \\
FSRP with open fishery & Total & 3581.87 & 85.592 \\
& Tokobushiabalone & 3.12 & 0.074 \\
& Cod & 74.4 & 1.777 \\
& Filefish & 106.35 & 2.541 \\
& Korean flounder & 418.92 & 10.000 \\
Total & Purplish Washington clam & 0.11 & 0.002 \\
& Total & 602.9 & 14.407 \\
& & 4184.77 & 100.000 \\
\hline
\end{tabular}

Socially accepted FSRP also provided time-demanding education and counseling to fishermen by experts having in depth knowledge on fisheries. In addition, a fisheries management committee was set up as a system to manage and operate FSRP. To build up awareness of fishermen, the fisheries management committee worked on strengthening public relations on rebuilding stocks of targeted fish species (Lee, 2008).

Management challenges of FSRP: Fisheries rebuilding operations have brought convincing results. However, there are some challenges to be considered to get the best output to continue a comprehensive national stock rebuilding approach with seasonal fishing closure. There are some other additional factors to be taken into consideration for making a successful policy integration to get a healthy marine environment in future.
The first challenge involves preservation of genetic resources. In Jeju, abalone showed a reduction of its genetic diversity probably due to intensive breeding within the same hatchery brood stock (An et al., 2010). Genetic drift in tokobushi abalone was also observed due to breeding practices among limited brood stocks in the same hatchery (An et al., 2011).

Thereafter, rebuilding plans were focused on maximizing stocks but did not pay attention to the reduction of unwanted bycatch species. Annual catches of purplish Washington clam, one of the 10 targeted species for FSRP, declined sharply due to mixed catching. Again, there are inherited limitations to assess the efficiency of enhanced strategies due to lack of data available and the fact that only few species are examined well enough to drive definite conclusions. For better result, some aspects such as environmental, production, migration and resources may be 


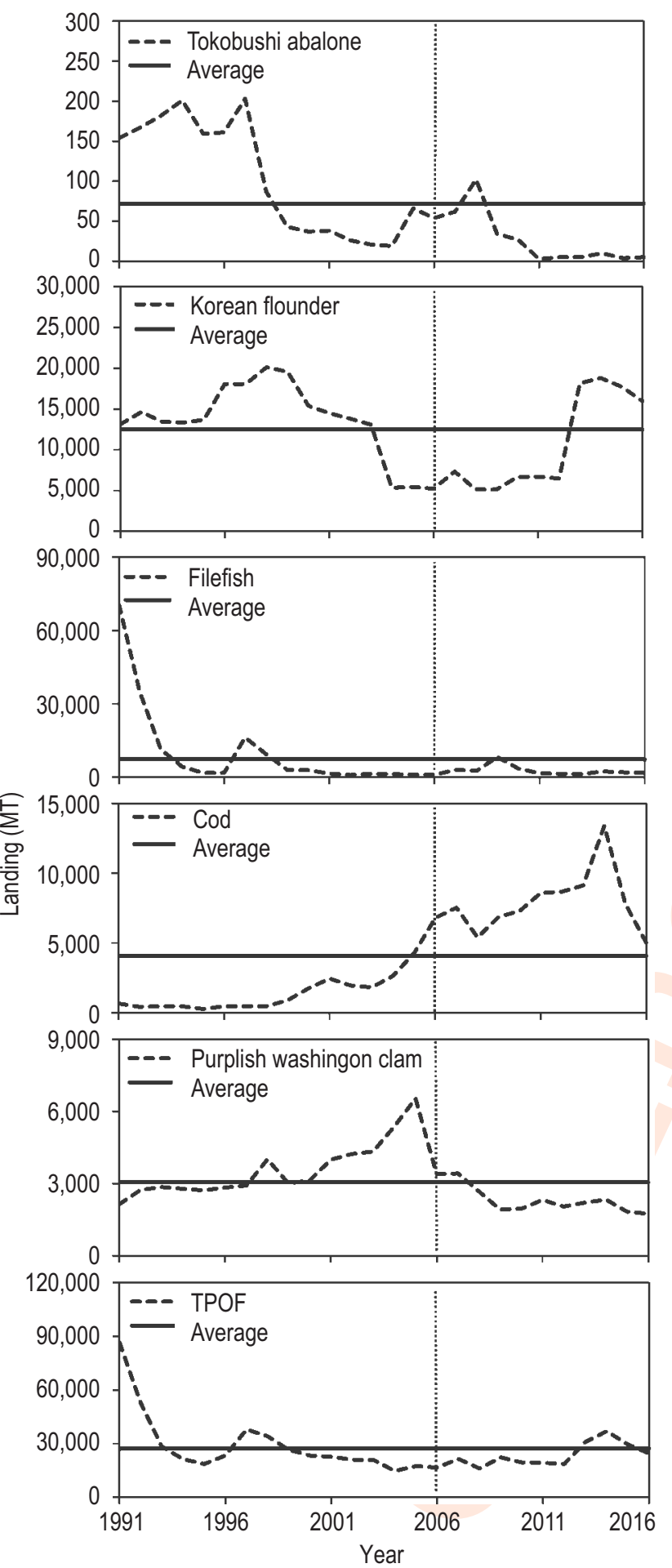

Fig. 3 : Annual production (1991-2016) of year-round open fishery.

taken into account to collect effective data and expand them to evaluate data in an appropriate way (NFRDI, 2001).

Furthermore, Korean coastal fisheries comprise multispecies harvesting for small-scale and commercial fishing industry. Thus, related species must be taken into consideration for carrying out ecosystem-based FSRP gradually for achieving goals to enhance stock (An et al., 2011). To compensate the loss in fishermen's profitability and also to ensure a successful rebuilding plan, market stabilization and some form of financial support may need to be provided to the fishermen community (NFRDI, 2004). Therefore, FSRP operation in Korea may not bring expected results unless proper attention is given to the adjacent Far East (China and Japan) for managing common marine resources (Ryu, 2004).

The seasonal closure has proved as a potential means of remedy to prevent a sudden declining in fisheries stocks. FSRP with seasonal closure provides more production than year-round open fishery. From a social perspective, fisheries enhancement has brought a better livelihood for increasing income in a consistent manner. Therefore, systematic research on the biology of species, mixed catches effects, hazard management and net income loss recovery of fishermen will be helpful to carry out fisheries rebuilding in the long run.

\section{Acknowledgments}

We acknowledge that this work was supported by a Research Grant 2020 from Pukyong National University, Korea. We also appreciate FIRA members for their cordial help by providing information for conducting this research.

\section{References}

Agriculture and Agri-Food Canada: Insight South Korea, the fish and seafood trade. Canada (2015). http://www.agr.gc.ca/resources/ prod/Internet-Internet/MISB-DGSIM/ATS-SEA/PDF/6590eng.pdf (accessed 14 January 2018)

An, H.S., S.W. Hong, E.M. Kim, J.H. Lee, J. K. Noha, H.C. Kim, C.J. Park, B.H. Min and J.I. Myeong: Comparative genetic diversity of wild and released populations of Pacific abalone Haliotis discus discus in Jeju, Korea, based on cross-species microsatellite markers including two novel loci. Anim. Cells Syst., 14, 305-313 (2010).

An, H.S., J.W. Lee, H.C. Kim and J.I. Myeong: Genetic characterization of five hatchery populations of the Pacific abalone (Haliotis discus hannai) using microsatellite markers. Int. J. Mol. Sci., 12, 4836-4849 (2011).

FAO: The state of world fisheries and aquaculture. Opportunities and challenges. Rome, Italy (2014).

FIRA: Fisheries Resources Agency, Business FIRA, Busan, South Korea (2017). http://www.fira.or.kr/english/english_010101.jsp (accessed 30 December 2017)

Gordon, H.S.: The economic theory of a common property resource: The fishery. J. Polit. Econ., 62, 124-142 (1954).

Ichinokawa, M., H. Okamura, C. Watanabe, A. Kawabata and Y. Oozeki: Effective time closures: Quantifying the conservation benefits of input control for the Pacific chub mackerel fishery. Ecol. Appl., 25, 1566-1584 (2015).

KFA: Korean Fisheries Yearbook, Korean Fisheries Association, South Korea (2017).

Kim, D.H.: Fish Stock Rebuilding Plans in Other Nations. Korea Maritime 
Institute (KMI), Busan, South Korea (2004).

Lee, S.G.: Marine Bioeconomics. Busan: Pukyong National University (PKNU); Busan, South Korea (2007).

Lee, S.G.: Policies of Rebuilding Fish Stocks. Designseasang, Busan, South Korea (2008).

Lee, S.G.: The economics of rebuilding fisheries in Korea: National comprehensive approaches. J. Pub. Admin. Pol. Res., 2, 20-27 (2010).

Lee, S.G. and A.R. Midani: National comprehensive approaches for rebuilding fisheries in South Korea, Mar. Pol., 45, 156-162 (2014).

Lee, S.G. and A.R. Midani: Productivity change under the vessel buyback program in Korean fisheries. Fish. Sci., 81, 21-28 (2015).

Lee, S.G. and M.A. Rahman: Ecological stock enhancement programs (ESEPs) based fisheries rebuilding plan (FRP) in Korea. J. Environ. Biol., 39, 936-942 (2018).

Merino, G., B. Manuel, J.A. Fernandes, C. Mullon, W. Cheung, V. Trenkel and V. Lam: Estimating the economic loss of recent North Atlantic fisheries management. Prog. In Oceanog., 129, 314-323 (2014).

NFRDI: Evaluations of Optimal Catch Ability for Major Offshore Fisheries in Korea, National Fisheries Research and Development Institute. South Korea (2001).

NFRDI: National Fisheries Research and Development Institute. A
Symposium on the Fish Stock Rebuilding Plan, Sejong, South Korea (2004).

Rice, J.C. and S.M. Garcia: Fisheries, food security, climate change and biodiversity: characteristics of the sector and perspectives of emerging issues. ICES J. Mar. Sci., 6, 1343-1353 (2011).

Ryu, J.G.: An Analysis on the institutional aspects of fisheries management and policy. Ministry of Ocean and Fisheries, South Korea (2004).

Simões, S.M., G.S. Heckler and R.C. Costa: Reproductive period and recruitment of penaeoidea shrimp on the south-eastern Brazilian coast: Implications for the closed season. Crustaceana. 90, 11771192 (2017).

UN: The Ocean Conference, the UN follows up on the Ocean Conference Voluntary Commitments for the implementation of Sustainable Development Goal 14. (2017). https://oceanconference.un.org/ UN-follows-up-on-the-Ocean-Conference-Voluntary-Commitments (accessed 16 October 2017)

Ye, Y., K. Cochrane, G. Bianchi, R. Wilmann, J. Majkowski, M. Tandstad and F.R. Carocci: Rebuilding global fisheries: The world summit goal, costs and benefits. Fish Fish., 14,1-12 (2012).

Zhang, C.I., S.C. Yoon and J.B. Lee: Effects of the 1988/89 climatic regime shift on the structure and function of the southwestern Japan/East Sea ecosystem. J. Mar. Sys., 67, 225-235 (2007). 